\title{
O JUDÔ NO PROGRAMA GOVERNAMENTAL BOLSA-ATLETA: A DISTRIBUIÇÃO ESPACIAL DOS BOLSISTAS (2011-2013) ${ }^{1}$
}

\author{
Yuri Rafael Dias \\ Universidade Federal do Paraná, Curitiba, Paraná, Brasil \\ Marcelo Moraes e Silva \\ Universidade Federal do Paraná, Curitiba, Paraná, Brasil \\ Katiuscia Mello Figuerôa \\ Universidade Federal do Paraná, Curitiba, Paraná, Brasil \\ Ricardo João Sonoda Nunes \\ Universidade Federal do Paraná, Curitiba, Paraná, Brasil \\ Jeferson Roberto Rojo \\ Universidade Federal do Paraná, Curitiba, Paraná, Brasil \\ Fernando Marinho Mezzadri \\ Universidade Federal do Paraná, Curitiba, Paraná, Brasil
}

\begin{abstract}
Resumo
O presente artigo tem por objetivo identificar como se deu a distribuição espacial dos atletas do Judô dentro do Programa Bolsa-Atleta entre os anos de 2011-2013. Para tanto, foram utilizados os dados fornecidos pelo Ministério do Esporte, que disponibilizou informações sobre os atletas contemplados com o benefício durante o recorte temporal do estudo, e também do sistema da Confederação Brasileira de Judô. Mediante a análise realizada, podemos concluir que os atletas tendem a se manter nas regiões mais desenvolvidas do país, estando concentrados nas regiões Sul e Sudeste, seguidas pelo Nordeste, Centro-Oeste e, por último, a região Norte.
\end{abstract}

Palavras-chave: Judô; Bolsa-Atleta; Financiamento Governamental.

\section{Introdução}

O Bolsa-Atleta é um importante programa governamental criado no ano de $2005^{2}$, através da promulgação da Lei $\mathrm{n}^{\circ} 10.891$ e regulamentada pelo Decreto 5.342 (BRASIL, 2004; 2005) que visa ampliar as fontes de financiamento esportivo no Brasil de uma forma

\footnotetext{
${ }^{1}$ O presente trabalho conta com o financiamento do Programa Nacional de Pós-Doutorado Institucional - PNPD Institucional, da Fundação Coordenação de Aperfeiçoamento de Pessoal de Nível Superior - CAPES.

${ }^{2}$ Em seu primeiro ano de existência o programa atendeu 975 atletas (MORAES E SILVA et al. 2014) e desde então vem crescendo em grandes proporções, atingindo seu apogeu no ano de 2013 com 5.691 atletas beneficiados. Os níveis de contemplação e valores das bolsas são, conforme aponta Corrêa et al (2014): a) Atleta de Base (R\$ 370,00); b) Estudantil, destinado aos estudantes que participem com destaque dos Jogos Escolares e Universitários Brasileiros ( $\mathrm{R} \$ 370,00)$; c) Nacional ( $\mathrm{R}$ \$ 925,00); d) Internacional (R\$1.850,00); e) Olímpico e Paralímpico (R\$3.100,00) e f) Bolsa-Pódio, em que os atletas devem estar classificados entre os 20 primeiros colocados no ranking mundial de sua modalidade/categoria (até $\mathrm{R} \$ 15.000,00$ ).
} 
diferente das demais ações que existiam até então, pois o financiamento é direcionado diretamente ao atleta sem intermediários no momento de receber o valor em dinheiro (CORRÊA, 2013; ANUNCIAÇÃO, 2014; CORRÊA et al. 2014; DIAS, 2014; MORAES E SILVA et al. 2014; 2015, 2015; REIS et al. 2015).

Dentre os esportes de destaque do país, o Judô é a modalidade que mais pódios conquistou em Jogos Olímpicos na história da participação do Brasil nesta competição, totalizando 19 medalhas, sendo três ouros; três pratas e 13 bronzes (CBJ, 2014a; COB, 2014). Em Munique (1972), Chiaki Ishii conquistou para o esporte sua primeira medalha (bronze), e após os jogos de 1984, em Los Angeles, a modalidade esteve presente nos pódios olímpicos em todas as edições do evento, tendo seu apogeu nos jogos de Londres com quatro medalhas: uma de ouro com a atleta Sarah Menezes e três de bronze com Felipe Kitadai, Rafael Silva e Mayra Aguiar (CBJ, 2014a). Inclusive, por virtude de todos estes resultados nas competições internacionais, a Confederação Brasileira de Judô é apontada, conforme assinalam Mazzei et al. (2012), como modelo de gestão esportiva dentro do cenário esportivo brasileiro.

Compreendendo os temas até aqui comentados como relevantes para o esporte nacional, julgamos necessário traçar um panorama nacional dessa modalidade que tanto se destaca, não somente no programa governamental supracitado, como também em diversas competições em nível internacional ${ }^{3}$.

Dessa forma, nossa intenção com o trabalho realizado foi a de verificar em quais regiões do país estão concentrados os atletas do Judô beneficiários do Programa Bolsa-Atleta e quais os locais de treinamento destes esportistas, utilizando o recorte temporal de 20112013.

\section{Metodologia}

O presente estudo insere-se na proposta metodológica indicada por Mezzadri et al. (2015), que preconizam um método para detectar os elementos quantitativos e qualitativos da política pública para o esporte no Brasil. A proposta ampara-se numa perspectiva de padronizar os métodos de investigação, visto que, conforme apontam os autores, existe uma deficiência neste tipo de estudos.

Entretanto, apesar da pequena quantidade de pesquisas, tem-se visto um aumento no número de estudos deste caráter, especialmente pela vontade dos pesquisadores em entender os motivos de sucesso e/ou fracasso de determinadas nações em competições esportivas internacionais (OAKLEY; GREEN 2001; GREEN; HOULIHAN, 2005; HOULIHAN, 2008). Característica que também começa a se cristalizar em algumas produções brasileiras (CORRÊA, 2013; ANUNCIAÇÃO, 2014; CORRÊA et al. 2014; DIAS, 2014; MORAES E SILVA et al. 2014; 2015; REIS et al. 2015).

A seleção da amostra utilizada foi delimitada no recorte temporal entre os anos de 2011-2013 do Programa Bolsa Atleta, do Ministério do Esporte (ME), regido pela Secretaria Nacional de Esporte de Alto Rendimento (SNEAR). A coleta de dados foi realizada através da elaboração de uma base de dados criada a partir da matriz analítica sistematizada por Mezzadri et al. (2015) e aplicada nos estudos de Anunciação (2014), Corrêa (2013), Corrêa et al. (2014), Dias (2014), Moraes e Silva et al. (2015) e Reis et al. (2015). A importância da construção de tal matriz surge no intuito de validar os dados obtidos e, com isso, realizar uma pesquisa empírica com dados consistentes.

\footnotetext{
${ }^{3}$ Nos campeonatos mundiais o país também se mostra uma potência no esporte. Já foi conquistado um total de 34 pódios - cinco ouros, dez pratas e 19 bronzes (CBJ, 2014b). É preciso destacar que 24 destas foram conquistadas na atual gestão da Confederação, que teve seu início em 2003. O auge neste evento veio em 2011 onde o país conquistou seis pódios (um ouro, três pratas e dois bronzes) (CBJ, 2014a).
} 
A base de dados construída para este artigo em específico apresenta um padrão único de sistematização que visa contemplar algumas informações sobre os atletas: a) Modalidade; b) Nome do Atleta; c) Classe Etária; d) Categoria de Peso; e) Data de Nascimento; f) Clube; g) Cidade do Clube; h) UF do Clube; j) Região do Clube; k) Sexo; 1) Cidade Natal; m) Estado Natal; n) Região Natal; o) Nível de Bolsa; p) Ano; q) Valor.

As linhas contêm dados recolhidos das planilhas da Controladoria Geral da União (CGU), não disponibilizadas on-line, fornecidas diretamente pelo Ministério do Esporte. Além disso, para essa etapa da pesquisa também foi utilizado o sistema on-line da Confederação Brasileira de Judô, nomeado Zempô. Nessa base de dados foram coletadas informações referentes aos clubes, cidade e estado do clube de cada atleta contemplado. Os dados da modalidade do Judô dos anos de 2011 a 2013 utilizados referem-se apenas aos atletas da modalidade convencional ${ }^{4}$ e preencheram um total de 660 linhas.

\section{Análise espacial do judô no programa bolsa atleta}

Conforme aponta uma série de estudos, o Bolsa Atleta é um dos mais importantes programas de apoio ao atleta no esporte brasileiro (CORRÊA, 2013; CORRÊA et al. 2014; MORAES E SILVA, et al. 2014; 2015; ANUNCIAÇÂO, 2014; REIS, et al. (2015). As pesquisas de Corrêa (2013) e Corrêa et al. (2014) indicam que o Judô se configura como o segundo esporte com maior número de atletas beneficiados em toda a história do programa, ficando atrás somente do Atletismo.

Nos três anos selecionados para amostra do presente estudo, o Bolsa Atleta forneceu um total de 13.116 de benefícios. Desse total, 660 são do Judô. Na tabela abaixo se observa a quantidade de bolsistas por ano na modalidade e no total do programa:

\begin{tabular}{ccccc}
\hline Ano & $\mathbf{2 0 1 1}$ & $\mathbf{2 0 1 2}$ & $\mathbf{2 0 1 3}$ & Total Geral \\
\cline { 2 - 5 } Total Geral & 3182 & 4243 & 5691 & $\mathbf{1 3 1 1 6}$ \\
Total Judô & 224 & 221 & 215 & $\mathbf{6 6 0}$ \\
\hline \% do Judô & $\mathbf{7 , 0 4 \%}$ & $\mathbf{5 , 2 8 \%}$ & $\mathbf{3 , 9 4 \%}$ & $\mathbf{1 , 7 1 \%}$ \\
Tabela 1 - Número total de contemplados no Programa Bolsa-Atleta e do Judô nos anos de 2011, 2012 e 2013 - Sistematizado \\
pelos autores.
\end{tabular}

Os dados da Tabela 1 mostram um fato no curioso. Como visto, o programa tem aumentado consideravelmente o número de benefícios concedidos. Tal crescimento decorre, conforme salientam Moraes e Silva et al. $(2014 ; 2015)$, pela proximidade das Olimpíadas de 2016, que serão sediadas no Rio de Janeiro. Afinal, existe um planejamento para que o Brasil fique entre os dez primeiros do ranking Olímpico e entre os cinco primeiros no Paralímpico. Por essas questões, investimentos significativos foram feitos no Bolsa Atleta. Contudo, apesar da tendência de aumento, podemos observar que existe uma redução ano a ano da quantidade de atletas beneficiados no Judô, números que se iniciam em 224 no ano de 2011, caem em 2012 para 221 e, por fim, para 215 no ano de 2013. Tais dados indicam que a modalidade pode ter encontrado seu platô de crescimento dentro do programa.

A próxima análise a ser realizada aborda a distribuição regional dos atletas. Contudo, antes de observar os dados sobre a distribuição das bolsas por região, torna-se necessário compreendermos o significado do conceito de regionalização:

\footnotetext{
${ }^{4} \mathrm{O}$ recorte com enfoque no esporte olímpico deu a entender que o esporte paralímpico precisa ser analisado em separado, no sentido de fornecer maior visibilidade para este campo. Mais detalhes sobre o Bolsa-Atleta no esporte paraolímpico consultar Reis et al. (2015).
} 
Regionalização é a divisão de um espaço ou território em unidades de área que apresentam certo número de características comuns que a individualizam. Os critérios para a regionalização são vários (físicos, políticos, socioeconômicos, etc.). As finalidades também podem variar. Elas podem ser políticas, econômicas, estatísticas, administrativas (para planejamentos) e didáticas (ensino da Geografia nas escolas). (SCHNEEBERGER; FARAGO, 2003, p.166).

Atualmente o Instituto Brasileiro de Geografia e Estatística (IBGE), seguindo os critérios da Constituição Federal, estabelece a divisão do território brasileiro em cinco grandes regionalizações: Norte, Nordeste, Centro-Oeste, Sudeste e Sul (BRASIL, 1988). Ao relacionar a questão da regionalização com a esfera esportiva, Corrêa et al. (2014, p.11) apontam os seguintes elementos:

Entendendo a importância de que um esclarecimento sobre a distribuição espacial da maioria de atletas que visam o rendimento favorece um maior planejamento para um investimento mais eficaz nas modalidades esportivas que possuem uma adesão regional. Um polo pode ser fomentado através de corretas políticas públicas para o esporte.

Nesse sentido, ao buscarmos compreender esta questão da regionalização o passo seguinte foi o de verificar a distribuição espacial dos atletas. Na amostra selecionada, o Judô se mostrou uma modalidade difundida em território nacional, chegando a contemplar 24 das 27 Unidades Federativas do Brasil. Com exceção dos estados do Acre, Mato Grosso e Rondônia, todos os outros possuem e/ou possuíram pelo menos um bolsista, conforme podese observar na Tabela 2:

\begin{tabular}{|c|c|c|c|c|}
\hline Estados & 2011 & 2012 & 2013 & Total Geral \\
\hline SP & 35 & 47 & 48 & 130 \\
\hline RJ & 32 & 32 & 38 & 102 \\
\hline RS & 21 & 28 & 24 & 73 \\
\hline$N / E$ & 40 & 19 & 9 & 68 \\
\hline MG & 17 & 24 & 20 & 61 \\
\hline MS & 9 & 14 & 15 & 38 \\
\hline PR & 7 & 10 & 12 & 29 \\
\hline SC & 8 & 11 & 9 & 28 \\
\hline PI & 8 & 5 & 6 & 19 \\
\hline $\mathbf{A M}$ & 8 & 3 & 5 & 16 \\
\hline $\mathbf{R N}$ & 8 & 4 & 1 & 13 \\
\hline $\mathbf{P E}$ & 4 & 4 & 4 & 12 \\
\hline PB & 6 & 4 & 1 & 11 \\
\hline$S / C$ & 3 & 6 & 2 & 11 \\
\hline $\mathrm{CE}$ & 3 & 1 & 4 & 8 \\
\hline DF & 4 & 3 & 1 & 8 \\
\hline GO & 3 & & 4 & 7 \\
\hline ES & 1 & 2 & 3 & 6 \\
\hline $\mathbf{A P}$ & & 2 & 2 & 4 \\
\hline $\mathbf{A L}$ & 2 & & 1 & 3 \\
\hline BA & 1 & 1 & 1 & 3 \\
\hline MA & 2 & & 1 & 3 \\
\hline
\end{tabular}




\begin{tabular}{c|ccc|c}
\hline PA & & 1 & 2 & $\mathbf{3}$ \\
\hline TO & 1 & & 1 & $\mathbf{2}$ \\
\hline RR & 1 & & & $\mathbf{1}$ \\
\hline SE & & & 1 & $\mathbf{1}$ \\
\hline Total Geral & $\mathbf{2 2 4}$ & $\mathbf{2 2 1}$ & $\mathbf{2 1 5}$ & $\mathbf{6 6 0}$
\end{tabular}

Tabela 2 - Quantidade de bolsas por Estado, divididos anualmente e geral - Sistematizado pelos autores.

São Paulo é o estado com o maior número de contemplados, totalizando 130 bolsas, o equivalente a 19,70\% do total. Em seguida vem o Rio de Janeiro com 102 benefícios $(15,45 \%)$ e em terceiro lugar o Rio Grande do Sul com 73 (11,06\%). No outro extremo têm-se os estados de Roraima e Sergipe com apenas um atleta beneficiado cada. Esses, porém, só aparecem nos anos de 2011 e 2013 respectivamente, não apresentando bolsistas no ano de 2012. Ainda no extremo inferior está o Tocantins, que aparece em antepenúltimo lugar com apenas dois esportistas. Caso semelhante aos dos estados do Pará, Maranhão, Alagoas, Amapá e Goiás, os quais não apresentam atletas no programa em pelo menos um ano da amostra.

Conforme pode ser visto na Tabela 2, existem duas classificações além das unidades federativas: $N / E$ e $S / C$. A primeira se refere a atletas que não foram encontrados no sistema Zempô da Confederação Brasileira de Judô ${ }^{5}$, o que pode ser um indício de que os esportistas abandonaram as práticas competitivas. Já a sigla $S / C$ demarca os atletas que na mesma época não possuíam nenhuma instituição em seu registro na confederação. Em ambos os casos os números podem ser considerados evolutivos - no ano de 2011 foram 40 os atletas que não foram encontrados no sistema, enquanto em 2012, foram apenas 19, resultando numa queda de mais de 50\%. Já em 2013 ocorre uma nova diminuição com apenas nove atletas que não tiveram seu registro localizado. Números que podem indicar que os atletas que recebem o benefício estão começando a dar continuidade à prática esportiva, mantendo com isso os resultados e o rendimento já alcançados, demonstrando que o Bolsa Atleta pode estar sendo uma política pública que colabora para o não abandono do esporte.

Da mesma forma, os esportistas que não possuíam instituições em seus registros no sistema da confederação se apresentam em número diminuto: três em 2011; seis em 2012 e dois em 2013. Esses números baixos são interessantes e curiosos, pois no Brasil, poucos são os clubes que adotam a política de "salários" aos seus atletas, podendo sugerir que estes tenham sido "dispensados" por seus clubes ou, talvez, que tenham até abandonado a vida esportiva ${ }^{6}$. Nesse sentido, os números decrescentes das classificações $N / E$ e $S / C$ demonstram que é possível trabalhar com a hipótese de que a Confederação Brasileira de Judô está abarcando e dando certo suporte aos atletas bolsistas, mostrando, conforme aponta Mazzei et al. (2012), que a referida instituição apresenta um modelo eficiente de gestão esportiva.

Nesse sentido, cabe realizar aqui uma apreciação semelhante à levantada pelas pesquisas de Corrêa (2013), Corrêa et al. (2014) e Reis et al. (2015), estudos nos quais os autores analisaram as distribuições de bolsas por regiões do Brasil. Estes estudos observaram a proximidade da esfera esportiva com a econômica. Afinal, existe uma maior predominância das bolsas nas regiões Sul e Sudeste do país, conforme pode ser visto na tabela abaixo:

\begin{tabular}{|c|c|c|c|c|c|c|c|c|c|c|}
\hline \multirow[b]{2}{*}{ Ano } & \multicolumn{2}{|c|}{ CENTRO OESTE } & \multicolumn{2}{|c|}{ NORDESTE } & \multicolumn{2}{|c|}{ NORTE } & \multicolumn{2}{|c|}{ SUDESTE } & \multicolumn{2}{|c|}{ SUL } \\
\hline & $\begin{array}{c}\text { Total } \\
\text { Região }\end{array}$ & $\%$ & $\begin{array}{c}\text { Total } \\
\text { Região }\end{array}$ & $\%$ & $\begin{array}{c}\text { Total } \\
\text { Região }\end{array}$ & $\%$ & $\begin{array}{c}\text { Total } \\
\text { Região }\end{array}$ & $\%$ & $\begin{array}{c}\text { Total } \\
\text { Região }\end{array}$ & $\%$ \\
\hline 2011 & 16 & $8,84 \%$ & 34 & $18,78 \%$ & 10 & $5,52 \%$ & 85 & $46,96 \%$ & 36 & $19,89 \%$ \\
\hline
\end{tabular}

\footnotetext{
${ }^{5}$ Atletas não foram encontrados na época de coleta de dados da pesquisa que ocorreu entre os meses de Agosto e Setembro de 2014 por motivos de não localização do registro ou nomes homônimos, que tornaram impossível a identificação precisa do atleta.

${ }^{6}$ Sobre o abandono no judô brasileiro consultar os trabalhos de Massa et al. (2010; 2014).
} 


\begin{tabular}{lllllllllll}
\hline $\mathbf{2 0 1 2}$ & 17 & $8,67 \%$ & 19 & $9,69 \%$ & 6 & $3,06 \%$ & 105 & $53,57 \%$ & 49 & $25,00 \%$ \\
$\mathbf{2 0 1 3}$ & 20 & $9,80 \%$ & 20 & $9,80 \%$ & 10 & $4,90 \%$ & 109 & $53,43 \%$ & 45 & $22,06 \%$ \\
\hline $\begin{array}{l}\text { Total } \\
\text { Geral }\end{array}$ & $\mathbf{5 3}$ & $\mathbf{9 , 1 2 \%}$ & $\mathbf{7 3}$ & $\mathbf{1 2 , 5 6 \%}$ & $\mathbf{2 6}$ & $\mathbf{4 , 4 8 \%}$ & $\mathbf{2 9 9}$ & $\mathbf{5 1 , 4 6 \%}$ & $\mathbf{1 3 0}$ & $\mathbf{2 2 , 3 8 \%}$ \\
\hline \multicolumn{8}{r}{ Tabela 3 - Comparação entre anos pelas regiões - Sistematizado pelos autores. }
\end{tabular}

Os dados mostram uma distância notável da região Sudeste das demais regiões. Esta apresenta $51,46 \%$ do total dos bolsistas, enquanto que a região Sul (segunda colocada) se mostra com 22,38\% seguida de pelo Nordeste com 12,56\%. Depois temos o Centro-Oeste com $9,12 \%$ e, por último, o Norte, com apenas 4,48\% dos beneficiados. Vale lembrar que nessa análise foram desconsiderados na porcentagem total os atletas classificados como $N / E \mathrm{e}$ $S / C$. Os dados mostram a predominância dos atletas nas regiões mais ricas do país. Tais números também podem indicar que determinados atletas tendem a migrar para as regiões mais desenvolvidas do Brasil em busca de uma estrutura maior de treinamento. Este quadro de predominância das regiões mais desenvolvidas se deve possivelmente por um dos fatores abaixo relacionados:

- Maior população e um número superior de praticantes da modalidade;

- Maior número de competições;

- Maior número de instituições financiadoras, ou seja, aquelas que pagariam alguma remuneração a seus atletas;

- Maiores infraestruturas para o treinamento;

- Maiores possibilidades de visibilidade em caso de se tornar campeão de uma categoria, devido ao fato de estarem presentes diversos técnicos, instituições e patrocinadores em um mesmo evento.

Esses fatores podem ser considerados fundamentais no momento de um atleta definir seu futuro esportivo. A análise de cada um destes pontos em estudos futuros se torna de vital importância, pois a partir disso, conforme aponta Massa et al. (2010; 2014), um esportista pode estar garantindo não somente a sua viabilidade como atleta de rendimento, mas também a forma como será visto, as competições que irá disputar, assim como o salário que poderá receber e etc. Estas questões levam ao próximo ponto a ser trabalhado: as instituições que os atletas representam.

No que se refere à distribuição por unidade federativa, os clubes com mais atletas beneficiados pelo programa estão no eixo Sul-Sudeste:

\begin{tabular}{cc}
\hline Estado & $\begin{array}{c}\text { Total de } \\
\text { Clubes }\end{array}$ \\
\hline SP & 25 \\
RJ & 11 \\
PR & 10 \\
MS & 8 \\
SC & 7 \\
PE & 6 \\
RS & 6 \\
DF & 5 \\
RN & 5 \\
AM & 4 \\
GO & 4 \\
\hline
\end{tabular}




\begin{tabular}{cc}
\hline MG & 4 \\
CE & 3 \\
ES & 3 \\
PB & 3 \\
AL & 2 \\
MA & 2 \\
PI & 2 \\
AP & 1 \\
BA & 1 \\
PA & 1 \\
RR & 1 \\
SE & 1 \\
TO & 1 \\
\hline Total de & 116 \\
Clubes & \\
\hline
\end{tabular}

Tabela 4 - Quantidade de instituições que possuem atletas bolsistas por estado - Sistematizado pelos autores

A unidade federativa mais rica do país aparece em primeiro lugar com 25 instituições que possuem atletas bolsistas, em segundo lugar o Rio de Janeiro com 11 e em terceiro o Paraná, com 10. A posição paranaense é até curiosa, visto que no total de quantidade de bolsas este ocupa somente o sétimo lugar. Tais números mostram que nessas unidades federativas o Judô está mais difundido, existindo uma maior presença de instituições e sem nenhuma que detenha certa hegemonia. Muito diferente de Minas Gerais (quatro clubes) e Rio Grande do Sul (seis clubes), que apesar da imensa tradição, aparecem em $12^{\circ}$ e sétimo lugar respectivamente em número de clubes com atletas bolsistas.

Os números levantados indicam que dentre os dez primeiros colocados na quantidade de instituições, somente cinco são das regiões Sul e Sudeste, o que nos leva a uma questão fundamental: um maior número de entidades está necessariamente ligado à quantidade de bolsas? Ao acompanhar o gráfico abaixo ${ }^{7}$, nota-se a predominância de algumas instituições tradicionais no cenário esportivo brasileiro:

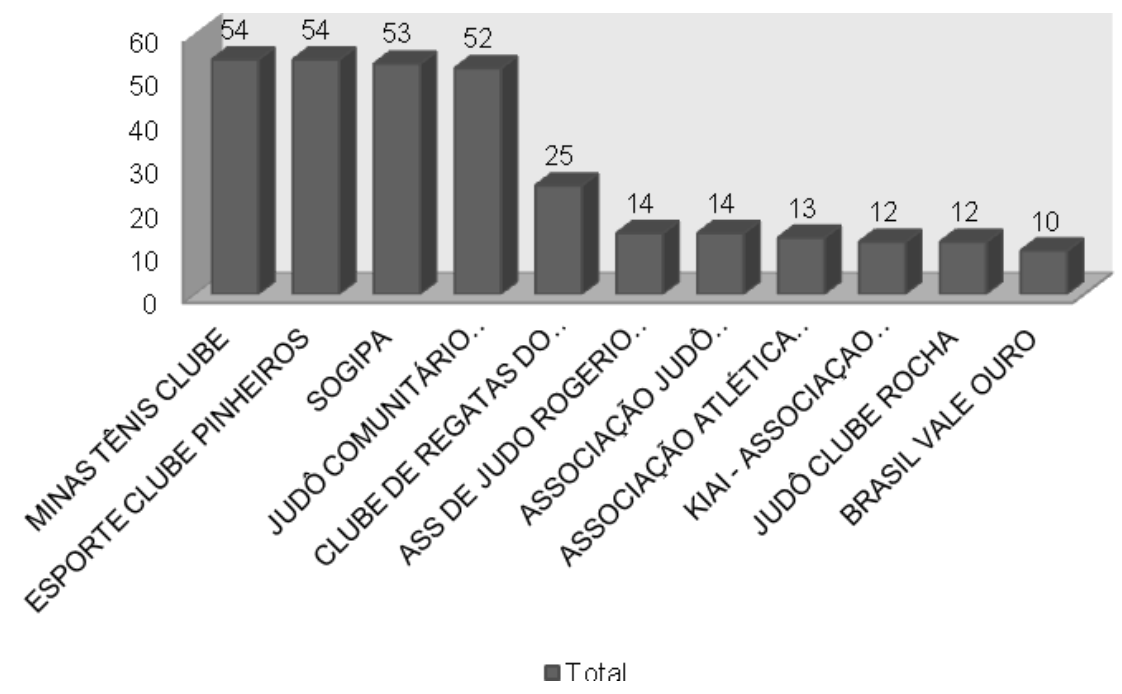

Gráfico 1: Clubes que possuem dez ou mais bolsistas entre os anos de 2011-2013 - Sistematizado pelos autores.

\footnotetext{
${ }^{7}$ No gráfico aparecem apenas os clubes com 10 ou mais bolsistas.
} 
Ao analisar o Gráfico 1 notamos que a amostra teve uma redução drástica. Das 116 instituições bolsistas, o gráfico limita-se a um pequeno número, ou seja, 11 agremiações. $\mathrm{O}$ que representa menos de $10 \%$ do total. Os dados mostram o quanto os atletas estão centrados em certos clubes e regiões do Brasil, visto que este seleto grupo de instituições representa $47,42 \%$ da amostra total de bolsistas. Tal fato se torna mais interessante se observarmos que a soma dos quatro primeiros colocados no gráfico ser de 213 contemplados, ou seja, 32,27\% do total do programa Bolsa Atleta no Judô. Tais números mostram o quão centrado está a prática competitiva deste esporte no Brasil, a ponto de mais de $30 \%$ dos beneficiados estarem distribuídos em apenas quatro de um total de 116 instituições que possuem esportistas agraciados com o auxílio governamental. Vale também a observação de que dentre as cinco primeiras associações deste gráfico, somente o Clube de Regatas do Flamengo não possui atletas olímpicos nessa amostra ${ }^{8}$.

De um modo geral, os 11 clubes de seis diferentes estados são instituições tradicionais na prática do Judô: São Paulo (Esporte Clube Pinheiros e Associação de Judô Rogério Sampaio), Rio Grande do Sul (KIAI - Associação Canoense de Judô e a SOGIPA), Rio de Janeiro (Brasil Vale Ouro, Clube de Regatas do Flamengo e Judô Comunitário Instituto Reação), Piauí (Associação Judô Queiroz - AJQ), Mato Grosso do Sul (Associação Atlética Judô Futuro e Judô Clube Rocha) e Minas Gerais (Minas Tênis Clube). Nesta amostra existem representantes de quatro regiões do país: Sul, Sudeste, Nordeste e Centro-Oeste. A região Norte não apresentou clubes com dez ou mais bolsistas, sendo que os que mais se aproximaram deste número foram as Associações Athlética Cagin e Shogum de Judô, ambas provenientes do estado do Amazonas, com cinco bolsistas cada.

Para explicar melhor essa questão dividimos as instituições em três categorias:

a) Clubes tradicionais: Minas Tênis Clube, Esporte Clube Pinheiros, SOGIPA e Clube de Regatas do Flamengo;

b) Associações comandadas por ex-atletas de renome internacional: Judô Comunitário Instituto Reação (Flávio Canto $^{9}$ ), Associação de Judô Rogério Sampaio (Rogério Sampaio ${ }^{10}$ );

c) Outras associações de destaque: Associação Judô Queiroz - AJQ, Associação Atlética Judô Futuro, Judô Clube Rocha, KIAI - Associação Canoense de Judô e Brasil Vale Ouro.

Vale também a comparação com a tabela de instituições por estado, na qual o Paraná se encontra em terceiro lugar em quantidade de clubes, porém, não apresenta nenhum representante com dez ou mais bolsistas, assim como os estados de Santa Catarina e Pernambuco $\left(5^{\circ}\right.$ e $6^{\circ}$ lugar respectivamente). Por outro lado podemos observar Minas Gerais que, apesar de não possuir um número significante de instituições, aparece com o clube que possui o maior número de atletas bolsistas (Minas Tênis Clube), em conjunto com Esporte Clube Pinheiros de São Paulo, ambos com 54 beneficiados, seguidos de perto pela SOGIPA do Rio Grande do Sul com 53, e pelo Judô Comunitário Instituto Reação, do Rio de Janeiro,

\footnotetext{
${ }^{8}$ As outras quatro instituições (Minas Tênis Clube, Pinheiros, Sogipa e Judô Comunitário) apresentam no período delimitado da pesquisa, atletas que competiram pelo Brasil em uma edição dos Jogos Olímpicos e que também foram beneficiados pelo Bolsa Atleta.

${ }^{9}$ Flávio Canto é um ex-judoca olímpico brasileiro, tendo participado das Olímpiadas de Atlanta em 1996 e Atenas em 2004. Nesta última conquistando uma medalha de bronze. Após se aposentar dos tatames funda o Instituto Reação. O ex-atleta também ocupa uma posição de destaque nos meios de comunicação de massa, sendo apresentador do programa Corujão do Esporte na TV Globo e do programa de lutas Sensei, no Sportv.

${ }^{10} \mathrm{O}$ ex-judoca Rogério Sampaio foi medalhista de ouro nos Jogos Olímpicos de Barcelona em 1992. Após sua aposentaria cria uma associação para o desenvolvimento de novos judocas no Brasil.
} 
com 52 contemplados. Todas estas instituições tem em seus quadros a presença de importantes atletas do judô brasileiro. Tais instituições são os principais ambientes esportivos institucionalizados tornando-se o local de produção e difusão de diversos elementos que acabam por estruturar todo o cenário do Judô no Brasil, pois tais entidades detêm o monopólio desse esporte no país. Afinal, inúmeros atletas de destaque estão vinculados a essas instituições, geralmente localizadas nas regiões mais desenvolvidas economicamente, o Sul e Sudeste do Brasil.

Os números analisados reforçam a centralização do benefício nas entidades localizadas nas regiões Sul e Sudeste, onde temos três estados destacados no Sudeste e 1 no Sul. Na região Centro Oeste e Nordeste temos apenas um estado representante em cada. Fato que consolida ainda mais o estudo de Corrêa et al. (2014) no que se refere às regiões supracitadas serem dominantes neste programa governamental.

\section{Considerações finais}

Durante o estudo foi possível visualizar o panorama de distribuição quantitativa e espacial do Judô brasileiro frente ao programa Bolsa Atleta. Dessa forma, observa-se que esta modalidade tem uma grande representatividade na política pública, sendo a segunda modalidade com maior número de contemplações (CORRÊA 2013; CORRÊA, et al. 2014; DIAS, 2014).

Mediante análise feita sobre a distribuição espacial dos atletas, notamos que a tendência apontada por Corrêa et al. (2014) de que esses tendem a se manter nas regiões mais desenvolvidas do país se confirma também no Judô, mostrando uma concentração nas regiões Sul e Sudeste. Essa distribuição pode ocorrer devido a diversos itens como os apontados nos estudos de Massa et al. (2010; 2014) e Dias (2014): um maior número de competições nos estados citados ou até mesmo a presença de instituições financiadoras. Porém, observamos que a quantidade de clubes presentes em determinadas regiões/estados não significa necessariamente que estes possuem destaque na formação de atletas. Como exemplo, temos o caso do estado do Paraná, que surge em $6^{\circ}$ lugar na quantidade de bolsistas, porém, em $3^{\circ}$ lugar nos números de clubes que possuem atletas beneficiados, fato no mínimo curioso, pois ainda que possua esta excelente colocação - que deixa o estado na frente do Rio Grande do Sul e Minas Gerais -, o Paraná se mantém atrás na quantidade de esportistas, um indicador de que o esporte se encontra mais pulverizado nesta Unidade Federativa, porém sem um grande destaque nas competições.

Visualizamos que a quantidade de clubes presentes nos estados não significa que esses possuem muitos atletas contemplados, fato confirmado pelo caso supracitado do Paraná, que surge em terceiro lugar na quantidade de clubes, que, entretanto, não possuem dez ou mais atletas beneficiados - a entidade que mais se aproximou deste número foi a Associação Esportiva Juventus com nove esportistas. Por outro lado, Rio Grande do Sul e Minas Gerais, que apresentam poucos clubes, possuem as associações com o maior número de atletas contemplados, juntamente com São Paulo e Rio de Janeiro. O que consolida a presença das entidades tradicionais no cenário esportivo brasileiro como o Esporte Clube Pinheiros (SP), SOGIPA (RS), Minas Tênis Clube (MG) e o Clube de Regatas do Flamengo (RJ). Clubes que são potências em quase todos os esportes olímpicos. Também temos que mencionar o Instituto Reação (RJ) e Associação de Judô Rogério Sampaio (SP), que são entidades renomadas na modalidade muito em virtude do valor simbólico de seus fundadores os medalhistas olímpicos Flávio Canto e Rogério Sampaio.

Estas análises puderam complementar o estudo de Corrêa (2013, p. 56), que também apontou algumas especulações sobre esse assunto: 
Se existe o êxodo dos atletas que fazem parte do programa para outros locais, mais especificamente a região Sudeste, não foi possível detectar, uma vez que há uma oscilação da quantidade de bolsistas entre as regiões. Somente é possível apontar a provável ocorrência. Entretanto, uma pesquisa futura que verifique nome por nome da listagem de atletas contemplados e cruze estes com as respectivas Unidades Federativas informadas a cada ano, poderá apontar a veracidade de tal hipótese, e se ainda assim esta investigação não puder fazê-lo, por conta da ambígua fonte que o Ministério do Esporte obtém estes dados, pode-se cruzar com informações oriundas das Confederações.

Para futuros estudos seria interessante analisar na íntegra a migração desses atletas, procurando visualizar e comparar os locais de nascimento com os lugares onde os esportistas estão treinando para visualizar esta migração dentro do território nacional. Porém, tais questões são outros Shiais ${ }^{11}$ a serem disputados...

\title{
JUDO IN THE "BOLSA-ATLETA" GOVERNMENTAL PROGRAM: THE SPATIAL DISTRIBUTION OF THE BENEFICIARIES (2011-2013)
}

\begin{abstract}
This paper aims to identify how was the spatial distribution of Judo athletes within the "Bolsa-Atleta" Program between the years 2011-2013. To achieve the goal, we used the data given by the Ministry of Sport, which provided information on athletes awarded with the benefit during the time frame of the study, and also those data obtained through the Brazilian Judo Confederation system. Through the analysis, we can conclude that athletes tend to remain in the most developed regions of the country, being concentrated in the South and Southeast, followed by the Northeast, Midwest and finally, the Northern region.
\end{abstract}

Keywords: Judo; "Bolsa-Atleta"; Governmental funding.

\section{EL JUDO EN EL PROGRAMA GUBERNAMENTAL "BOLSA-ATLETA": LA DISTRIBUCIÓN ESPACIAL DE LOS BECARIOS (2011-2013)}

\section{Resumen}

El presente artículo tiene por objetivo identificar cómo era la distribución espacial de los deportistas del Judo dentro del Programa "Bolsa-Atleta" entre los años 2011-2013. Para lograr el objetivo, fueron utilizados los datos proporcionados por el Ministerio del Deporte, que proveyó informaciones sobre los deportistas que tuvieron el beneficio durante el recorte temporal del estudio, así como aquellos datos obtenidos a través del sistema de la Confederación Brasileña de Judo. Tras el análisis realizado, podemos concluir que los deportistas tienden a permanecer en las regiones más desarrolladas del país, concentrándose en las regiones Sur y Sudeste, seguidas por Nordeste, Centro-Oeste y, finalmente, la región Norte.

Palabras clave: Judo; "Bolsa-Atleta"; Financiamiento Gubernamental.

\footnotetext{
${ }^{11}$ Vocabulário em japonês utilizado no Judô que significa Competição.
} 


\section{Referências}

ANUNCIAÇÃO, F. N. O atletismo no programa governamental "Bolsa Atleta": primeiros apontamentos (2011-2013). 2014. 61f. Monografia (Graduação em Educação Física) Departamento de Educação Física. Universidade Federal do Paraná, Curitiba 2014.

BRASIL. Constituição da República Federativa do Brasil: Texto constitucional promulgado em 5 de outubro de 1988.

Lei $\mathbf{n}^{0}$ 10.891, de 9 de julho de 2004. Institui o Programa Bolsa-Atleta.

Decreto $\mathrm{n}^{\circ} 5.342$ de 14 de janeiro de 2005. Regulamenta a Lei $\mathrm{n}^{\circ} 10.891$, de 9 de julho de 2004, que institui o Programa Bolsa-Atleta.

COMITÊ OLÍMPICO BRASILEIRO (COB, 2014). Brasil nos jogos, Desempenho esportivo em evolução. Disponível em: <http://timebrasil.cob.org.br/brasil-nos-jogos〉. Acesso em: 22 nov. 2014.

CONFEDERAÇÃO BRASILEIRA DE JUDÔ. (CBJ, 2014a). Judô Nacional, Galeria de Campeões. Disponível em: <http://www.cbj.com.br/galeria_campeoes>. Acesso em: 23 nov. 2014.

(CBJ, 2014b). Seleção brasileira escalada para o Mundial de Judô 2014. Disponível em: <http://www.cbj.com.br/noticias/4045/selecao-brasileira-escalada-para-o-mundial-dejudo-2014-.html>. Acesso em: 23 nov. 2014.

CORRÊA, A. J. Financiamento do esporte olímpico brasileiro: mapeamento inicial do programa "Bolsa-Atleta". 86f. Monografia (Graduação em Educação Física) - Departamento de Educação Física. Universidade Federal do Paraná, Curitiba, 2013.

CORRÊA, A. J.; MORAES E SILVA, M.; MEZZADRI, F. M.; CAVICHIOLli, F. R. Financiamento do esporte olímpico de verão brasileiro: mapeamento inicial do programa Bolsa-Atleta (2005-2011). Pensar a Prática, Goiânia, v. 17, p. 1-15, 2014.

DIAS, Y. R. O Judô no Programa Governamental Bolsa-Atleta: primeiros apontamentos (2011-2013). 68f. Monografia (Graduação em Educação Física) - Departamento de Educação Física. Universidade Federal do Paraná, Curitiba, 2013.

GREEN, M.; HOULIHAN, B. Elite sport development: Policy learning and political priorities. London: Routledge, 2005.

HOULIHAN, B. Sport and Society. Sage publications LTD. - London, 2008.

MASSA, M.; UEZU, R.; BÖHME, M. T. S. Judocas olímpicos brasileiros: fatores de apoio psicossocial para o desenvolvimento do talento esportivo. Revista Brasileira de Educação Física e Esporte, São Paulo, v.24, n.4, p.471-81, out./dez. 2010

MASSA, M.; UEZU, R.; PACHARONI, R.; BÖHME, M. T. S. Iniciação Esportiva, tempo de prática e desenvolvimento de judocas olímpicos brasileiros. Revista Brasileira de Ciências do Esporte, Florianópolis, v. 36, n. 2, p. 383-395, abr./jun. 2014. 
MAZZEI, L. C.; VIEIRA, D. E. B.; SILVA NETO, A. M.; BASTOS, F. C. Gestão da Confederação Brasileira de Judô. Revista Intercontinental de Gestão Desportiva, São Paulo, vol.2, n.1, p. 30-42, jan./jun. 2012.

MEZZADRI, F. M.; MORAES E SILVA, M.; FIGUERÔA, K. M. Desenvolvimento de um método para as pesquisas em políticas públicas de esporte no Brasil. Motrivivência, Florianópolis, v. 27, n. 44, p. 49-63, maio/2015.

MORAES E SILVA, M. SANTOS, N. CORRÊA, A. J. A configuração do financiamento do governo brasileiro ao esporte de rendimento. In: MEZZADRI, F. M. (Org.). Políticas Públicas e Esporte. Várzea Paulista, SP: Fontoura, 2014. p. 93-113.

MORAES E SILVA, M.; MEZZADRI, F. M.; SOUZA, D. L.; SOUZA, P. M. O financiamento público do rúgbi brasileiro: a relação governo federal e Confederação Brasileira de Rugby (CBRu). Revista da Educação Física/UEM, Maringá, v. 26, n. 2, p. 245-286, 2015.

OAKLEY, B.; GREEN, M. Elite sport development systems and playing to win: Uniformity and diversity in international approaches. Leisure Studies, 20, p. 247-267, 2001.

REIS, R. E.; MORAES E SILVA, M.; FIGUERÔA, K. M.; ALMEIDA, B. S.; MEZZADRI, F. M. Dez anos do programa federal "Bolsa Atleta": uma descrição das modalidades paralímpicas (2005-2014). Pensar en Movimiento: Revista de Ciencias del Ejercicio y la Salud, San José, v. 13, n. 2, p.1-18, 2015.

Recebido em: 05/10/2015

Revisado em: 18/01/2016

Aprovado em: 10/02/2016

Endereço para correspondência: moraesmarc@yahoo.com.br

Marcelo Moraes e Silva

Universidade Federal do Paraná

Rua XV de Novembro, 1299

Centro, Curitiba - PR

80060-000 